\title{
Migrações e Diversidade na Cidade Empreendedora: Definindo o cenário para os novos imaginários urbanos
}

Nuno Oliveira ${ }^{1}$

\section{Resumo}

A partir de trabalho de campo em Lisboa e Buenos Aires, o artigo examina como os processos de regeneração e revitalização do centro da cidade têm sido consistentemente ligados à mobilização da diversidade cultural. A pesquisa etnográfica e qualitativa foi realizada em espaços urbanos específicos onde a regeneração dirigida pela cultura se encontra a ser levada a cabo. A seleção desses espaços foi baseada na ideia de evitar os suspeitos usuais em estudos urbanos, como as grandes capitais do hemisfério norte. Argumentamos que os traços culturais dos imigrantes são trazidos para esses processos por meio de mecanismos mediadores específicos dos modelos das cidades empreendedoras. Integramos em nossa análise uma ampla gama de atores envolvidos na governança urbana, desde autoridades municipais, passando por organizações de imigrantes, até empreendedores migrantes, a fim de fornecer uma interpretação completa de tais mecanismos. Mostramos que as cidades buscam estratégias similares de lidar com a diversidade cultural de origem imigrante, estando nestas implicadas três dimensões principais: estetização, marketing de lugar e "ethnic showcasing". Levantamos algumas questões conceituais e políticas relacionadas com os novos regimes de visibilidade e formas de organização social da diferença específicas da cidade empreendedora.

\section{Palavras-chave}

Diversidade cultural. Governança urbana. Imigrantes. Marketing urbano. Cidades globais.

\begin{abstract}
Drawing from field work in Lisbon and Buenos Aires, the paper examines how processes of regeneration of the inner-city have been consistently linked to cultural diversity mobilization. Ethnographic and qualitative research was carried out in specific urban spaces where culture-led regeneration is underway. The selection of such spaces was premised on the idea of avoiding the usual suspects in urban studies such as the big capitals of the northern hemisphere. We argue that migration cultural traits are brought into such processes through cultural mediatory mechanisms that are specific to entrepreneurial cities' models. We integrate in our analysis a wide range of actors involved in urban governance, from municipal authorities, through immigrant
\end{abstract}

\footnotetext{
${ }^{1}$ Investigador integrado de pós-doutoramento no CIES. E-mail: nuno.filipe.oliveira@iscte-iul.pt.
} 
organizations to migrant entrepreneurs in order to provide a complete interpretation of such mechanisms. Findings show that cities pursue similar strategies of coping with migrant-driven cultural diversity implying three main dimensions: aestheticization, place marketing and "ethnic showcasing". We raise some conceptual and policy related questions about new regimes of visibility and forms of social organization of difference specific to the entrepreneurial city..

\section{Keywords}

Cultural diversity. Urban governance. Migrants. Urban marketing. Global cities.

\section{Introdução: a diversidade urbana e a paisagem intercultural}

Neste artigo baseio-me na literatura sobre diversidade cultural urbana discutindo alguns aspectos da sua mobilização enquanto estratégia de desenvolvimento das cidades. Neste sentido, situo-me no conjunto de preocupações que interpelam a ideia de que a etnicidade pode ser usada estrategicamente na política cultural urbana (KALTMEYER, 2011; FINCHER, IVESON, LEITNER; PRESTON, 2014; RACO, 2018; FRANTZ, 2018). Por conseguinte, procuro mobilizar literatura sobre a diversificação do viver social nas cidades globalizadas contemporâneas assim como o seu lugar estratégico nas políticas de renovação e desenvolvimento urbano. Devemos considerar a diversidade como um fenómeno urbano, e como tal deve ser este investigado. Há uma literatura prolixa sobre como essa diversidade deixou de estar contida em enclaves específicos e definidos, passando a proliferar no todo urbano, simultaneamente adquirindo configurações múltiplas que escapam às delimitações etnoculturais (VERTOVEC, 2007; WESSENDORF, 2013; WISE; VELAYUTHAM, 2014). Essa constatação não é apenas uma medida descritiva da transformação urbana, mas antes uma mudança nas formas de ler o objecto diversidade. Leitura que passa também pelas formas sociais através das quais o discurso da diversidade é captado. Neste texto preocupo-me com as formas como as redes de governança urbana mobilizam a diversidade cultural no interior do modelo da cidade empreendedora (HARVEY, 1989). E neste sentido importa não apenas olhar para os distribuidores de poder público e institucional, mas também para a própria agência dos imigrantes. Contra os suspeitos do costume, situados nas sociedades afluentes do hemisfério norte, neste artigo trago à colação dois espaços que surgem pouco (se alguma vez) nas análises comparativas. Trata-se de Buenos Aires e Lisboa, e a respeito das suas políticas urbanas de incorporação da diversidade, pergunto o que 
partilham e onde se separam. Como veremos, para além da dimensão social dos contextos, pouco há a separá-las, sendo a sua inclusão nas redes de poder multiescalares mais significativa do que a singularidade das suas histórias e desenvolvimento estrutural. Ou seja, apesar do hiato assinalável entre os dois espaços urbanos, as estratégias que produzem as suas centralidades definemse segundo princípios e lógicas semelhantes porque se encontram numa relação estrutural idêntica com o sistema de competição urbana global. A esse propósito, o conceito de paisagem cunhado por Zukin (1991) ilustra bem o fenómeno de valorização económica da diversidade cultural. Segundo a autora, as paisagens "devem ser perspectivadas como simbólicas, como expressões de valores culturais, comportamentos sociais, e acções individuais exercidas sobre localidades particulares no decorrer do tempo" (18). Essa definição envolve igualmente redes de poder e relações sociais localizadas, a qual se deve, a meu ver, ser complementada com a noção de paisagens de consumo (RITZER, 2005), salientando deste modo a associação actual entre práticas de consumo e a própria experiência da paisagem cultural onde estas decorrem. Nesse contexto, os significados e usos da cultura pública funcionam, como refere Zukin (1988, p. 260), como uma cartografia da receptividade da diversidade, que nos permite conceptualizar e representar a cidade. E é justamente nessa intersecção que a economia simbólica acolhe e engendra segundo os seus próprios requisitos a diversidade cultural trazida, sobretudo, pelas comunidades imigrantes.

\section{A cidade empreendedora e a "vantagem da diversidade"}

Devemos a David Harvey (1989) a conceção segundo a qual o modelo de organização das cidades contemporâneas é um modelo de empreendedorismo. $\mathrm{Na}$ comparação que traça entre os modelos de governança dos anos 60 e 70 e os atuais, Harvey salienta a passagem de um modelo de política urbana gestionária para a implementação de um modelo de governança urbana empreendedor. Esse empreendedorismo urbano sustenta-se fundamentalmente em lógicas de concorrência, quer internas - relativamente aos recursos do Estado - quer externas - relativas ao posicionamento das cidades numa hierarquia de competição global. A propósito do último aspeto, as cidades podem competir internacionalmente, reposicionando-se na "divisão espacial do consumo" (ibid, p. 9). Significaria, para Harvey, que as agendas de desenvolvimento urbano têm apostado na regeneração urbana, que gera dividendos através da inovação cultural, melhoramentos das estruturas físicas, 
gentrificação, consumo e entretenimento. Sobretudo, nas palavras do autor, "a cidade tem que surgir como um espaço inovativo, excitante, criativo e seguro para viver ou visitar, para nela distrair-se e consumir" (id. ibidem).

Ora a presença dos imigrantes nos contextos urbanos contemporâneos tem sido tendencialmente pensada e integrada em modelos de "vantagem da diversidade" (WOOD; LANDRY, 2008), ou seja, o cosmopolitismo das cidades, quando integrado numa estratégia de desenvolvimento urbano que combina a promoção da economia simbólica, nomeadamente através de indústrias criativas, e a implementação de condições para o consumo cosmopolita, produz uma vantagem comparativa no universo global de competição entre cidades.

Florida (2002) associa a diversidade a vantagens competitivas e alerta os decisores políticos para tornar as suas cidades mais diversas (embora aqui a diversidade extravase a mera diversidade etnocultural). Tomando especificamente a diversidade etnocultural, Syrett e Sepúlveda (2011, p. 488) elencam as várias formas como esta tem sido utilizada numa perspectiva diferenciadora dos recursos de cada cidade. Tanto através do branding urbano como da promoção dos negócios étnicos, ou das redes de comércio diaspóricas, passando pela promoção de bairros e festivais étnicos, as autoridades urbanas têm procurado explorar um "diversity dividend" que coloque as suas cidades numa hierarquia global de preferências. Com efeito, em muitos países "diversidade" tornou-se praticamente uma injunção política central (AHMED; SWAN, 2006, p. 570). A promoção da diversidade societal e o seu mainstreaming surgem como objectivos principais nas políticas dos dois lados do Atlântico (VERTOVEC, 2012; KALTMEYER, 2011) com especial relevo para as políticas urbanas. É nesse contexto de governança que na prática as políticas culturais que têm por vocação proteger a diversidade etnocultural não se distinguem da necessidade de enfatizar o seu potencial económico. Por exemplo, Wood (2012) classifica o modelo de governança actual das cidades ocidentais como neoliberal integrationism. Um tal modelo compreenderia formas estritas de migração, geralmente associadas a razões economicistas, bem assim como imposição de formas de verificação da lealdade identitária à sociedade de acolhimento. Embora Wood sublinhe que na América-Latina outras formas de governança imperam, aqui sustentamos que tanto a prática como as estruturas de significado são similares, senão idênticas, como o caso de Buenos Aires patenteará.

No caso europeu, recentemente foi assinalado que existe uma ligação directa entre a "viragem intercultural" na política europeia e a governança urbana (ABDOU; GEDDES, 2017). Como já afirmado, essa implicação tem por 
efeito incidir quer a prática da governança quer a sua análise numa economia política do espaço. A esta associa-se estreitamente a noção segundo a qual a diversidade é um recurso que deve ser aproveitado nas estratégias de regeneração urbana ou de revitalização dos centros urbanos, sobretudo nas suas materializações mais evidentes de "interculturalismo folclórico" (CAPONIO; RICUCCI, 2015) sustentados em festividades de natureza étnica ou etnicizada. $\mathrm{O}$ espaço público ganha naturalmente uma centralidade nas políticas das cidades. Muito dessas políticas joga-se no aproveitamento de recursos étnicos para a regeneração e reaproveitamento dos espaços públicos simbólicos da cidade. Como dito, a forma como a diversidade é integrada na política cultural da cidade está intrinsecamente ligada a um modo de governança próprio à cidade empreendedora, assim como a definiu David Harvey. Um dos aspectos focados por Harvey (2001) como centrais nesse novo modelo é a forma como as cidades procuram ser mais competitivas no que respeita a divisão espacial do consumo, com especial relevo para a combinação entre património cultural e marketing urbano. Propomos, por conseguinte, a imprescindibilidade de entrar em linha de conta com os novos modelos de empreendedorismo urbano onde a cultura empreendedora, assim como as lógicas de criatividade, reconstroem as subjectividades migrantes ${ }^{2}$.

Para ilustrar a importância que o discurso e a prática da celebração da diversidade têm granjeado nas estratégias urbanas, servimo-nos das iniciativas em torno da diversidade cultural que têm vindo a ser implementadas em Lisboa e Buenos Aires. Não pretendemos ser exaustivos, o que seria inexequível no espaço de um artigo. Mas apenas assinalar como alguns dos mecanismos de produção da cidade cosmopolita são comuns, e daí extrair algumas conclusões sobre a governança da diversidade. No caso vertente tratase das políticas e iniciativas urbanas que incidem sobre o centro de Lisboa, mais concretamente do centro histórico de Lisboa, onde residem a maioria dos cidadãos estrangeiros, e num segundo caso, de Buenos Aires, sobretudo no que toca a sua principal iniciativa, o festival cultural Buenos Aires Celebra.

\footnotetext{
2 Ver também a esse propósito o artigo de Feldman-Bianco (2009) sobre a reconstrução das imagens dos imigrantes portugueses em New Bedford, no Estado de Massachusets, e como esta levou igualmente ao reposicionamento da comunidade na economia global e, consequentemente, a uma nova subjectividade migrante.
} 


\section{Diversidade cultural em Lisboa e Buenos Aires}

Antes de nos debruçarmos sobre os casos propriamente ditos, convirá contextualizar em matéria de dados sobre diversidade cultural. Estes correspondem, com imperfeições diversas, aos dados que estão acessíveis sobre imigrantes quer ao nível nacional quer das cidades. Os dados mais fiáveis para Buenos Aires são os constantes do censo (2010), que representam o stock de estrangeiros legais à data. Segundo os dados do SEF (Serviço de Estrangeiros e Fronteiras), em 2016, residiam, em Lisboa, cerca de 55 mil cidadãos estrangeiros. A proporção de população estrangeira em Lisboa é, assim, superior à do país (em 2011, os estrangeiros correspondiam a 3,4 \% dos residentes) ${ }^{3}$. Lisboa é o segundo concelho do país com maior número de estrangeiros residentes, seguindo-se a Sintra. Da mesma forma, é na unidade administrativa denominada Cidade Autónoma de Buenos Aires (CABA) que se observa a maior concentração de estrangeiros residentes, apro ximadamente um milhão de pessoas (941.830, de acordo com os dados dos Censos de 2010) 4 . A diversidade de origens apresenta igualmente as suas peculiaridades. Assim temos que em Lisboa as principais nacionalidades residentes são a brasileira, chinesa, nepalesa, cabo-verdiana e francesa. Para Buenos Aires, o padrão corresponde a uma forte imigração dos países limítrofes, na medida em que a maior comunidade é a do Paraguai, seguida da Bolívia, Itália, Uruguai e Perú. Contudo, e contrariamente a Portugal, a Argentina é um país formado pela imigração, nessa medida apresentando um caleidoscópio de comunidades provenientes já do início do século XX, quando a imigração chegou a constituir $30 \%$ da população total 5 . Note-se, contudo, que essa distribuição populacional não possui reflexos diretos nos casos que abordaremos em seguida.

O foco deste artigo é a governança da diversidade cultural nas duas cidades com especial relevo para as práticas celebratórias dessa mesma diversidade. Embora diferenciados quanto aos aspetos sociográficos e geográficos - no sentido de que se trata de analisar, num caso, uma zona da cidade com forte implantação de minorias, e no outro, onde tal não se verifica - , partilham da ideia de utilizar a diversidade cultural como elemento das políticas de

\footnotetext{
${ }^{3}$ SEF. Relatórios estatísticos 2017 (Disponível em: https:/ / sefstat.sef.pt/Docs/Rifa2016.pdf).

${ }^{4}$ Disponível em: https://www.estadisticaciudad.gob.ar/eyc/?cat=291

${ }^{5}$ Informe sobre migraciones en Argentina:

https://www.cac.com.ar/data/documentos/11_Informe\%20sobre\%20Migraciones.pdf e Estadistica Ciudad, https://www.estadisticaciudad.gob.ar/eyc/?cat=291 [Acesso em: 24 out. 2019].
} 
desenvolvimento urbano.

O mesmo se passa com as duas cidades aqui abordadas. Apesar das incomensuráveis diferenças entre elas, há coisas que partilham. Uma das principais é ambas registrarem níveis muito assinaláveis de crescimento turístico e o facto de a economia dos seus países em muito se basear nesse sector. O poder de atração do turismo e de geração de uma economia do turismo possui pesos muito idênticos nos dois contextos. Assim, temos que na Argentina 10,3 \% do PIB era gerado pela AETV6 (dados de 2017). Para Portugal, observamos que a produção total do sector do turismo correspondia a 12,5\% do PIB em 2017. Em Lisboa, a contribuição do sector do turismo era de 14,5\% para a economia da cidade (dados de 2014) ${ }^{7}$, enquanto para Buenos Aires a contribuição era de 6,4\% em 2013, sendo que a capital federal representava à data $36 \%$ de todas as actividades turísticas em nível nacional ${ }^{8}$. Ou seja, apesar de significativas diferenças de história e desenvolvimento estrutural ou de configuração étnica, o peso que o turismo possui na economia dos dois países aproxima-os para efeitos analíticos, sobretudo quando atendemos ao facto de haver uma estreita ligação entre a mercadorização do étnico e a zonificação do turismo. Um outro aspeto no qual encontramos afinidades significativas para a organização das políticas urbanas é no plano simbólico.

Com efeito, em ambos os contextos encontramos uma matriz históricocultural relacionada com o hibridismo, sincretismo, e a combinação de formas e contribuições culturais do "outro". Assim temos que em Buenos Aires existe uma continuidade entre uma narrativa fundacional da nação de imigrantes e o aproveitamento das expressões etnoculturais contemporâneas, isto apesar de tradicionalmente a Argentina pautar a sua identidade nacional pela ficção da branquitude e da europeinidade (ALBERTO; ELENA, 2016). Em Lisboa, e mais especificamente em Portugal, a narrativa prende-se directamente com alguns tropos do lusotropicalismo, nomeadamente a ideia de que estamos em presença de um povo particularmente afeto à miscigenação (OLIVEIRA, 2015, para o caso de Lisboa).

\footnotetext{
${ }^{6}$ Actividad Economica de Turismo y Viaje en Argentina. Informe preparado para la Cámara Argentina de Turismo.

7 Revista comemorativa dos 20 anos da ATL

(https://www.visitlisboa.com/sites/default/files/2017-03/RTL_Fev17.pdf, p. 38 e segs)

8Impacto económico del turismo en la ciudad de Buenos Aires. Estimaciones para los anos 2004/2013, Autoridades Gobierno de la Ciudad de Buenos Aires, Mayo 2015. https://turismo.buenosaires.gob.ar/sites/turismo/files/IMPACTO\%20ECONOMICO\%20DEL\% 20TURISMO\%20EN\%20LA\%20CIUDAD\%202015-2.pdf [Acesso em: 21 mar. 2018].
} 
A iniciativa sobre qual nos focámos em Buenos Aires é a Buenos Aires Celebra. Houve diversas razões para esta escolha, mas, sobretudo, o facto de ela surgir referida sistematicamente pelos nossos entrevistados como a mais importante iniciativa no governo da diversidade cultural na cidade de Buenos Aires. O que é o Buenos Aires Celebra? Trata-se de uma celebração de rua organizada pelo Governo da Cidade de Buenos Aires em parceria com as colectividades imigrantes. Em dias geralmente coincidentes com datas simbólicas dos países de origem dessas colectividades, são organizados mercados de rua com comidas típicas acompanhados de espectáculos de dança e música, também eles tradicionais dos países da colectividade organizadora. Outras ocasiões há em que se celebram regiões, como o Caribe, por exemplo, juntando um conjunto de origens; ou os afrodescendentes, relevando as origens africanas da população de diversas nacionalidades. Buenos Aires Celebra ocorre na central (tanto em termos espaciais como simbólicos) Avenida de Mayo, construída em honra da revolução de Maio de 1820, que deu a independência à Argentina. A Avenida de Mayo é uma das artérias centrais da cidade de Buenos Aires que liga a famosa Plaza de Mayo, onde se situa o palácio do governo, com a Plaza de los dos Congressos, onde se encontra o parlamento da nação argentina. A avenida tem uma história que faz parte da própria história da cidade de Buenos Aires, com os seus prédios altivos e burgueses onde outrora residiam as famílias abastadas e da elite política bonairense. A escolha do espaço para a realização da Buenos Aires Celebra alia assim a ordem carismática com as intencionalidades da nova governança urbana.

Actualmente é um lugar de turismo, de empresas e escritórios de profissões liberais cujo movimento se articula com as ruas adjacentes e suas perpendiculares, lugar de intensa actividade comercial e consumista. A sua centralidade não pode ser exagerada quando se pensa que até recentemente albergava todos os serviços administrativos do Governo da Cidade (até 2016). Contudo, não constitui uma zona de particular concentração residencial de imigrantes. Na realidade, a maioria dos imigrantes reside nos bairros periféricos e precários. Mas é sem dúvida uma das zonas mais frequentadas por turistas e bonairenses, porque, entre outas coisas, serve de ligação entre a Plaza de Mayo e a axial Avenida 9 de Julio, lugares estratégicos de turismo e comércio. Em contraste com muitas das outras artérias da cidade de Buenos Aires, não há lojas de comerciantes imigrantes, algo que é típico em tantos bairros bonairenses quando se pensa nas mercearias, propriedades de bolivianos e peruanos; as tinturarias e pequenos mercados, propriedades quase 
exclusivas de chineses e coreanos, ou as lojas de tecidos, roupas e bric-a-brac, propriedades de judeus (no bairro do Onze), paulatinamente transformadas pelos mais recentes ocupantes chineses em armazéns de produtos importados. Na Avenida de Mayo essa diversidade é apenas para lá transplantada nos dias da feira do Buenos Aires Celebra.

Em contraste, em Lisboa, a zona que abrange a Mouraria e Almirante Reis tem uma história diferente, bem assim como uma composição material e estrutural distinta. É uma zona que recobre a parte histórica da cidade de Lisboa, abarcando o traçado medieval da zona da Mouraria, alargando-se depois pelas ruas burguesas de Arroios. Os dois locais que constituem a incidência principal do nosso estudo pertencem contudo a unidades administrativas diferentes. A Mouraria à Junta de Santa Maria Maior e o eixo da Almirante Reis, à Junta de Arroios.

Trata-se das duas freguesias com mais estrangeiros residentes na cidade de Lisboa. Com efeito, em Arroios residem estrangeiros de mais de 60 nacionalidades diferentes. Nas zonas partilhadas pelas antigas Juntas de Freguesia englobadas actualmente nas duas Juntas mencionadas atrás, a sua população era composta por $23,5 \%$ de estrangeiros, o que para o total da cidade de Lisboa representava, aproximadamente, $8 \%$ dos estrangeiros residentes. Destes, há a destacar a sobrerrepresentação de imigrantes de origem asiática, em particular oriundos do Bangladesh, do Nepal, da China e da Índia. Como veremos, em algumas ruas, essa presença é quase exclusiva de uma das nacionalidades, qualificando-as praticamente como nichos étnicos. Para além disso, há uma sobrerrepresentação dos imigrantes no comércio retalhista.

Em contraste com o caso argentino, a diversidade cultural é endógena aos locais, colocando a sua exibição na ordem da convivialidade local, mesmo que esta envolva, como por diversas vezes, actores exteriores à área urbana considerada. De resto, as festividades mais emblemáticas nesse território, se excluirmos a festa tradicional de Lisboa dos Santos Populares9, estão relacionadas com a diversidade cultural. Primeiro, com o festival intercultural Todos (antes de migrar para paragens adjacentes), depois com a Volta ao Mundo em Arroios, na praça do Areeiro, e, finalmente, com a celebração do Ano Novo Chinês na praça do Martim Moniz e bairro de Arroios. Num outro molde, os passeios interculturais organizados por uma associação cultural devem também figurar nesse conjunto. Qualquer desses eventos mobiliza discursiva e imageticamente a diversidade cultural e os seus benefícios.

${ }^{9}$ Festas tradicionais religiosas que coincidem com o início do Verão. 


\section{Buenos aires - a cidade onde há sempre algo que fazer!}

Começo esta secção citando um slogan do governo da cidade de Buenos Aires, porque considero que ele condensa numa frase (como é suposto os slogans fazerem) o que pode ser a articulação entre a governança da diversidade e as suas expressões produzidas pelos grupos imigrantes e a incorporação em estratégias de valorização do centro e marketing urbano.

Todavia, há uma anotação que deve ser feita. Se atentarmos para a maioria dos trabalhos produzidos sobre segregação espacial e localização urbana em Buenos Aires, constataremos que a maioria dos imigrantes se encontra nas zonas mais degradadas e fragilizadas socialmente da cidade metropolitana (DI VIRGILLIO et al.., 2015, p. 47). Não sendo este um texto sobre segregação espacial, afigura-se-nos, contudo, importante assinalar tal disparidade, porque ela tem reflexos naquilo que poderíamos chamar de geografia da celebração da diversidade. Contrariamente ao que seria esperado, ou seja, que a maioria das celebrações ocorressem nos locais de maior concentração de estrangeiros, estas são localizadas nas zonas de nível socioeconómico mais elevado. Quer seja a Plaza de Mayo, naquilo que os autores designam a cidade central, quer nas praças e jardins dos bairros de Belgrano e Recoleta ${ }^{10}$, o que esse padrão mostra é que há uma nítida prossecução de enobrecimento da diversidade cultural.

Neste sentido, a política da diversidade cultural em Buenos Aires mostra uma selecção criteriosa do espaço público, em que a visibilidade da primeira possa ser potenciada com ganhos para a política cultural da cidade.

A iniciativa mais relevante, e por esse facto mais mediatizável da cidade de Buenos Aires, é a Buenos Aires Celebra. Como foi dito, essa é uma iniciativa que em geral ocorre no centro da cidade, numa das suas avenidas mais típicas e nevrálgicas - a Avenida de Mayo. Na apresentação de Buenos Aires Celebra diz-se que o projecto cumpre um duplo objectivo: as colectividades mostrarem a sua cultura, história e identidade e que esta possa ser partilhada pelos habitantes e turistas. Esse intuito declarado encerra os principais eixos de compreensão de tais iniciativas.

Na estratégia cultural de Buenos Aires para 2030, começada a ser esboçada em 2016, a retórica da vantagem da diversidade impregna toda a programação e discurso ${ }^{11}$. Naquele que é considerado "El Primer Plan Estratégico de Cultura

\footnotetext{
${ }^{10}$ Ambos bairros de classe média-alta.

${ }^{11}$ Aprovação do plano estratégico para a cultura da cidade de Buenos Aires 2030. Disponível em: https://www.youtube.com/watch?v=Gi0pUdH9YDs]
} 
de la Ciudad Autónoma de Buenos Aires (LIBERMAN, 2016) quer a diversidade cultural quer de género figuram proeminentemente. E com estas, a noção segundo a qual a cultura é uma ferramenta central na transformação das dinâmicas urbanas "en favor de la identidade, en favor de la competitividad, en favor de la integración". O projecto elaborado pelo Consejo de Planeamiento Estratégico - Ciudad Autónoma de Buenos Aires, ou COPE ${ }^{12}$, estabelece que se trata de uma política que entra em linha de conta com um leque alargado de actores diferenciados tendo em consideração os contributos singulares para a produção do cosmopolitismo.

Essa visibilização faz parte das retóricas da cultura pública, ou seja, das representações da cidade enquanto "receptiva aos estrangeiros, tolerante com a diferença, e possibilitadora da partilha de uma vida socializada, tanto cívica como comercial" (ZUKIN, 1995, p. 260). Como diz em entrevista um dos representantes políticos responsável por essa iniciativa, Ter uma cidade na qual convivem, numa quase harmonia perfeita, mais de 40 coletividades de todo o mundo, é um valor muito destacável que não acontece em muitas cidades do mundo.".

Um segundo aspecto é que as ideologias de representação da cidade não atingem somente, ou prioritariamente, os seus habitantes. Tais expressões de cultura pública como reflexo das práticas nos espaços públicos são direccionadas e incorporadas nos fluxos globalizados de cultura e capital. O turismo, como um dos principais produtos de uma cultura globalizada do consumo sustentada por indivíduos com extrema mobilidade (JUDD, 2003), é um dos alvos de tais retóricas. Isso mesmo é atestado pela forma como a Buenos Aires Celebra foi criada.

Em 2011, Claudio Avruj assume a posição de subsecretário de Direitos Humanos da cidade de Buenos Aires. Nessa ocasião, agrega-se a expressão pluralismo cultural e cria-se a Direcção Geral de Colectividades. A direcção transpunha, ganhando em recursos e autonomia, o modelo de relação com os representantes dos imigrantes proveniente dos tempos em que Avruj era Director de Relações Internacionais do governo da cidade. Esse modelo é interessante em si mesmo de especificar.

Em tal espaço de negociação dos sentidos da diversidade, tem havido uma clara preferência por formas adaptadas à mercantilização dos espaços públicos e da cultura urbana por parte dos atores envolvidos. As questões de identidade de grupo funcionam como uma extensão da cultura e do património da cidade,

${ }^{12}$ Consejo de Planeamiento Estratégico 
e essa visão é oficialmente apoiada e produzida pelos próprios representantes dos migrantes. Por exemplo, a visão de um responsável público encontra respaldo nas declarações do representante da Federação Argentina de Colectividades, como segue:

A cidade de Buenos Aires entende que as comunidades são núcleos que conformaram a idiossincrasia dos portenhos [residentes originais de Buenos Aires] desde o início da cidade [...] e que fazem uma contribuição muito importante para a bagagem e a identidade cultural da cidade. Considera-se fazer parte dos Direitos Humanos da Cidade e faz parte do património cultural da Cidade (Responsável do Governo da cidade de Buenos Aires).

O ponto mais alto é uma iniciativa chamada "Buenos Aires Celebra". É ou ajudou a tornar visíveis as comunidades, porque todo fim de semana na Avenida de Mayo, que é uma avenida simbólica especialmente para os espanhóis, as comunidades são apresentadas com danças, fantasias, gastronomia, música [...] Isso [a idéia] surgiu quando Claudio Avruj era o secretário de direitos humanos da cidade. Ele encarregou-se disso e imaginou que poderia ser interessante para as próprias comunidades e para a Argentina funcionar como um pólo de atração para os turistas, em primeiro lugar, e também chamar a atenção do próprio portenho [...] (Responsável da Federação Argentina de Coletividades).

Os representantes das comunidades de origem imigrante são activamente incentivados a participar dessas estratégias e estruturas, quer pelo Governo da Cidade, através de um gabinete específico criado no seu interior, a Dirección General de Colectividades, quer pela própria Federação Argentina de Colectividades.

Parece haver uma grande unanimidade em considerar que a Argentina é um "mosaico de culturas", conforme diz um dos entrevistados, ecoando uma outra definição de geografias distintas (os Estados Unidos, e a célebre definição de Park da cidade como um mosaico de culturas). Todavia, é importante perceber que essa variedade nem sempre teve acolhimento nas narrativas da identidade nacional. Com efeito, as elites da Argentina moderna, pelo menos até à viragem do século XXI, sempre se dissociaram da narrativa da miscigenação como as que sustentaram o mito da democracia racial nos países vizinhos, como o Brasil, talvez o caso mais representativo dentre os países da América Latina (SEGATO, 2007). Contudo, a investigação actual aponta para um profundo revisionismo da ideia de branquitude argentina e do 
apagamento, muitas vezes compulsivo e violento, das suas origens étnicas e raciais. Entre outras coisas, verifica-se que o mito da origem europeia branca encontra-se a ser gradualmente substituído por uma construção de identidade mestiça e multicultural (ALBERTO; ELENA, 2016), em que a diversidade de origens raciais e étnicas é reconhecida. Essa "nova" narrativa encontrou reforço tanto através de instituições estatais como de organismos antirracistas, assim como na miríade de iniciativas promovidas pela sociedade civil. A nova tendência multicultural faz parte da sociedade argentina desde os anos 1980, com o surgimento do discurso dos direitos humanos, posteriormente intensificada com os governos peronistas de Fernando e Cristina Kirchner, durante os quais a retórica de "um povo que veio dos barcos "(ou seja, de origem europeia) ficou sujeita à revisão.

Dito isto, no espaço de negociação dito de governança, uma clara preferência pelas formas ajustadas à marketização dos espaços públicos e da cultura urbana tem sido a orientação privilegiada pelos actores implicados nesse mesmo espaço.

Todavia, essas transacções não são despojadas de contradições ou de tensões. O economicismo, segundo a classificação de diversos implicados, que essas iniciativas encerram não deixa de colidir com uma busca identitária que se elabora segundo o padrão discursivo do reconhecimento. Dar a conhecer as raízes culturais das suas colectividades funciona como uma estratégia de consolidação da pertença cultural e social. Paralelamente, apresenta ramificações muito concretas na criação de mais-valias através de artefactos e práticas culturais. Com efeito, a comercialização da identidade surge sistematicamente invocada como o motor para essas iniciativas. Tais invocações e lógicas de acção já não se resumem à noção de comércio étnico, dado que elas são incorporadas às grandes iniciativas bem para além do espaço da relação étnica, seja comercial, seja de outra natureza.

Assim, o financiamento associativo passa em larga medida pela forma como as entidades sobrevivem no mercado do étnico. Este apresenta-se como um espaço de concorrências, intra e intergrupos, ou colectividades. Espaço de mercadorização da identidade por definição, ele prima pela pureza das suas práticas; quer dizer, a cultura tem que ser uma competência pura, no sentido que Bourdieu dava ao gosto puro. Mas este, como é sabido, não era mais do que a eufemização de práticas interessadas.

Para ilustrar essa afirmação, trazemos uma pequena vinheta etnográfica que reflecte a mercantilização de traços culturais. Na celebração do Ano Novo Chinês de 2018 em Belgrano, um bairro de Buenos Aires, um grupo de 
comerciantes curdos que se encontravam presentes para vender shawarma foi instado a remover o seu stand de vendas porque colidia com as expressões "reais" da cultura chinesa. A razão era que o cone de carne num espeto não era compatível com a dança do dragão que, entretanto, invadira a avenida principal. Mediante uma perda considerável, os curdos cortaram a sua carne em pequenas fatias e venderam-na anunciando "sanduíches de carne chinesas", o que deixou de constituir um problema para os organizadores. Essa vinheta aparentemente insignificante ilustra como a "pureza" étnica pode ser manipulada pelos membros do grupo que representa e também por grupos externos para se ajustar às iniciativas culturais promovidas pelas cidades.

Se os actores representantes das colectividades se veem activamente conduzidos a participar dessas estratégias e enquadramentos, não o fazem, contudo, sem resistência. Entre a pureza da apresentação dos traços da "sua" cultura em contexto celebratório e a possibilidade de recolher proventos económicos, interpõe-se, para alguns membros das colectividades, não apenas estratégias de sobrevivência individual como processos de açambarcamento de capital social. Quer isto dizer que a presença em tais celebrações e o capital reticular $^{13}$ que ela envolve estruturam o espaço de possibilidades e a concorrência dos membros das respectivas colectividades. Como um entrevistado explicita,

Às vezes, vendem-se por uma feira. Eu dou-te um exemplo. (...) Nós éramos nove países, sessenta estandes, vinte e oito de xxxx. Depois de apresentarmos esse projecto e fizemos o primeiro Buenos Aires Celebra, tivemos muitos inconvenientes, porque os outros países disseram que éramos muitos e os ofuscávamos. Nós retirámo-nos da Celebra. Isso foi no ano passado (...) Duas semanas depois tivemos a nossa própria festa em outro lugar (...) dissemos que não nos vendíamos por uma feira. Há muitas pessoas que não têm senso de coletividade, mas sim de negociantes. E isso não é ser uma comunidade. ((Representante de associação de imigrantes venezuelanos, Buenos Aires).

Por outro lado, qualquer dessas celebrações é despojada de uma linguagem política mais imediata. Na medida em que, em virtude da sua centralidade espacial e simbólica, a Avenida de Mayo ainda abriga hoje a maioria das

13 Baseio-me para este termo na noção de network capital (URRY, 1988). Segundo Urry, este consistiria na capacidade de aceder a suportes de mobilidade e a uma panóplia de objectos e recursos, capacidade essa que funciona como matriz da desigualdade social. Distingo da mais clássica noção de estruturas de oportunidade pelo seu fraco ou inexistente grau de institucionalização. 
manifestações políticas e protestos sociais, a natureza celebratória e estetizante desses eventos contrasta com a efervescência política que se encontra associada a essa localização. Nesse contexto, entendo por estetização uma esfera de ação desprovida de conteúdo político e estruturada por sociabilidades sensíveis e experienciais. Certamente que esta possui uma ambiguidade assinalável. O caso do ano novo chinês em Buenos Aires é, porventura, o mais paradigmático em termos de articulação entre estetização e posicionamento social da coletividade.

Refira-se que a comunidade chinesa mantém um discurso significativamente idêntico nas duas cidades estudadas (Buenos Aires e Lisboa). Este surge, quer em Lisboa quer em Buenos Aires, como o potenciar de uma "marca cultural chinesa" 14.

Em ambos os casos, o governo da china apoia no sentido da "promoção da cultura chinesa no exterior", e em ambos os países recebe o apoio das autoridades municipais (no caso de Lisboa) ou governamentais (no caso de Buenos Aires), para que a sua celebração tenha uma visibilidade máxima e um máximo aproveitamento do espaço público. Em ambos os discursos se salienta o facto de as celebrações não estarem confinadas a um espaço guetizado, como seriam as velhas chinatowns, circunscritas a um bairro da cidade. A celebração passa a ser assimilada iconograficamente pela cidade e deixa de ser meramente expressão para o interior de uma dada comunidade, no caso vertente, a chinesa. Como diz a responsável pela organização do evento em Buenos Aires,

As pessoas têm um conhecimento básico por meio da TV, e do idioma chinês, mas, como temos muito mais a oferecer, decidimos criar esa empresa para introduzir um pouco mais do básico da sociedade. Hoje, oferecemos à sociedade argentina tudo o que tem a ver com história, cultura. (...) É a nossa marca. ((Representante da associação cultural chinesa responsável pela organização do evento).

O que esse exemplo mostra é que outros actores, como embaixadas ou empresários, constituem o espaço de relações que é igualmente o espaço de construção de uma determinada ideia de diversidade. Esta não é indissociável dos processos de governança que gerem a diversidade e as suas construções discursivas.

${ }_{14}$ Entrevista com representante da embaixada chinesa em Lisboa; e representante associativo chinês, Buenos Aires. A expressão é utilizada por ambos. 
Os actores parecem estar dispostos a ajustar as suas acções e estratégias à estrutura simbólica de uma cultura de marca, e a exibição étnica é adoptada como uma oportunidade de dar a conhecer a "autêntica" identidade do seu grupo. Mesmo que isso represente basicamente as danças tradicionais, comida e rituais, reduzidas a formatos improvisados e vendáveis.

Esses eventos são muito positivos porque reafirmam nossa identidade, nossa comunidade e dão visibilidade, o que é muito importante. As pessoas pensam que somos muito poucos, mas somos muito agora. (Empresário imigrante cubano, Buenos Aires).

[...] Porque é um grande evento em que mostram sua beleza tanto em instrumentos musicais quanto em peças de roupa. Porque em Setembro estamos perto do Carnaval, então para eles é uma vitrine. (Representante de uma associação brasileira, Buenos Aires).

Buenos Aires Celebra insere-se numa estratégia de revitalização do centro através de eventos e iniciativas culturais. Nas estratégias de regeneração urbana, sobretudo nas suas materializações mais evidentes de "interculturalismo folclórico" (CAPONIO; RICUCCI, 2015) através de festividades de natureza étnica ou etnicizada, o espaço público ganha naturalmente uma centralidade nas políticas ditas interculturais. Muito dessas políticas se joga no aproveitamento de recursos étnicos para a regeneração e reaproveitamento dos espaços públicos simbólicos da cidade. No Buenos Aires Celebra não é uma acção política que é colocada em evidência, como tantas outras iniciativas que se dão naquele espaço semanalmente. Pelo contrário, as intenções do Buenos Aires Celebra surgem como estritamente economicistas, se bem que apontando a ganhos simbólicos.

A floclorização que é criticada pelos académicos em geral é, contudo, apreciada e reproduzida pelas colectividades envolvidas. Longe da crítica que vê nessas iniciativas reproduções de versões anacrónicas da cultura ou suas versões despolitizadas, os envolvidos percepcionam tais iniciativas como oportunidades para angariar recursos para as suas associações e para avançar posições estratégicas através dos seus brokers para quem o acesso a recursos políticos importa. Convém, no entanto, referir que essa aparência celebratória encobre não apenas os recursos diferenciados das colectividades (sobretudo quando se tem em conta as diversas temporalidades da presença no território) como o leque de problemas com que muitas delas se confrontam. Em contraste, a sua contribuição para as geografias da diversidade deve ser entendida no 
plano de uma economia política do espaço, na qual a revitalização do centro nas suas modalidades de entretenimento é o fulcro da política da diversidade.

\section{Lisboa - quanto mais diversa, mais cool}

A cidade de Lisboa tem vindo a abandonar a natureza semiperiférica que lhe conferia a posição portuguesa no sistema mundo, aproximando-se gradualmente das grandes cidades do centro e, inclusivamente, rivalizando com elas em matéria de fluxos globalizados que estruturam as economias urbanas centrais. É nesse contexto político e económico que devemos situar as novas formas de governo da diversidade cultural, também elas reelaboradas enquanto governança.

A área da Mouraria e do Eixo Almirante Reis-Martins Moniz, sobre a qual se debruça este artigo, corresponde com grande acuidade a um processo de zonificação do turismo. Não descreveremos aqui os traços culturais e sociais desse espaço, remetendo o leitor para artigos anteriores (OLIVEIRA; PADILLA, 2017; OLIVEIRA, 2015, 2013). Contudo, vale a pena referir que a turistificação de espaços específicos da cidade de Lisboa possui um impacto concreto na estruturação das práticas socioespaciais e com ela no lugar da diversidade nas espacialidades e representações da vida urbana.

Devemos, por conseguinte, entender esse renascimento da zona MourariaAlmirante Reis no mais amplo âmbito da política cultural da capital. Lisboa tem desde cedo colocado a cultura na sua agenda de desenvolvimento. As diversas Visões que foram produzidas por especialistas em conjunto com decisores políticos e responsáveis pelo planeamento tomaram a cultura como um aspecto central da política de regeneração urbana. Esta surge como dimensão transversal a uma gama de atributos e características urbanas, desde a promoção da vida local, através de uma lógica de aproveitamento cultural e patrimonial dos bairros lisboetas, passando pelo seu património monumental propriamente dito.

Uma das formas que tem merecido um particular destaque é a diversidade cultural enquanto património de grupos de imigrantes, ou seja, aquilo que poderíamos designar por dimensão étnica da sua vivência citadina. O aproveitamento desta última como integrável num projecto mais vasto de culturalização da política de desenvolvimento urbano quadra com a intenção de cosmopolitizar a cidade. Com efeito, o espaço que aqui nos concerne ocupa esse lugar simbólico de centro cosmopolita, onde as várias tendências e mobilidades se encontram e concentram. 
Se em Buenos Aires uma tal representação estava presente na ideia de uma "cidade mosaico", em Lisboa ela emerge nessa zona específica enquanto espaço de mistura das "suas muito e variadas gentes"15; como espaço de uma interculturalidade concreta, caldeada por uma história de encontros globais.

Nessa esteira, as autoridades lisboetas têm feito uma aposta a todos os títulos assinalável na promoção da diversidade cultural da sua cidade. Talvez poucas cidades na Europa tenham colocado a diversidade cultural tão no centro da sua política de desenvolvimento urbano como Lisboa. A nível das políticas camarárias, a diversidade cultural tornou-se transversal aos vários domínios práticos e políticos. Desde logo, a implicação directa da promoção das vidas migrantes com o programa cultural da cidade. Se no primeiro documento de estratégia para a cidade, elaborado em 1992, as minorias migrantes então em crescimento ainda eram equacionadas enquanto potenciais "ilhas étnicas", na actualização desse mesmo programa, em 2012, a ideia de diversidade como uma vantagem será profusamente utilizada. No seguimento desse documento, os programas estratégicos da cidade de Lisboa colocam a questão do "cosmopolitismo" como objectivo central, o que nos permite interrogar o que significa o especial potencial de Lisboa para "o equacionar do cosmopolitismo" (CML, 2010, p.35) ${ }^{16}$. O próprio documento esclarece que se trata do crescimento das classes médias e da diversidade étnica que levará ao aparecimento de novos estilos de vida.

Essa intenção aproxima-se da estratégia do "urban renaisance" analisado por Zukin (1988) enquanto fenómeno de pós-suburbanização; ou seja, a atracção de novos públicos e contingentes residenciais para o centro da cidade, e a concomitante construção de novas centralidades. A cultura surge assim não como o domínio do imediatamente familiar, mas como objecto de consumo, que induz oportunidades no desenvolvimento da cidade. No entanto, isto não significa que a introdução da ideia da diversidade, e o seu correlato, os imigrantes, seja inteiramente instrumental. Com efeito, o campo de aplicação de políticas de imigração não se esgota na "vantagem da diversidade", havendo uma genuína preocupação em institucionalizar as condições de integração dos imigrantes, designadamente através de um Programa Municipal de Integração dos Migrantes, que aborda um leque alargado de domínios de actuação. Esse é um contraste que deverá ser feito com a política de cidade em Buenos Aires, que apesar de, como observámos, colocar em

\footnotetext{
${ }^{15}$ Entrevista com responsável da CML, Departamento de Direitos Ssociais, realizada em 2014.

${ }^{16}$ Carta Estratégica de Lisboa 2010-2024 - Um compromisso para o futuro da cidade.
} 
grande centralidade (inclusive territorial) a expressão das suas colectividades, ou a importância da diversidade cultural imigrante, só recentemente a linguagem da "vantagem da diversidade" surge em documento orientador da política cultural da cidade.

Nas dinâmicas de governança por nós observadas, os atores mais centrais para o desenvolvimento de práticas de visibilidade da diversidade cultural são, sobretudo, os empreendedores culturais (inclusivamente associados às autoridades públicas), os representantes político-estatais das próprias comunidades, como sejam as embaixadas, e, finalmente, os poderes locais e associações empresariais. Note-se que as associações de imigrantes têm um papel subsidiário nesses processos. Assim, o ano novo chinês em Lisboa conta, sobretudo, com o apoio da embaixada da China, da Câmara de Lisboa e de empresários chineses, salientando-se o promotor principal, o Hai Tong Bank que, com o respaldo da câmara de Lisboa, organizam no centro da cidade aquela que é conhecida como a mais importante celebração do calendário chinês.

Se atentarmos que as raízes de uma tal celebração eram, para o caso de Londres, e conforme descritas por Vickery e Vikery (1974), contrahegemónicas, percebemos que algumas das práticas culturais desse grupo foram apropriadas pela lógica que associa espaços de consumo cultural com a produção de símbolos cosmopolitas nas novas centralidades da cidade de Lisboa. Combinação esta cujo interesse não passa somente pela regeneração dessa nova centralidade, mas também com investimentos políticos do Estado de origem da respectiva comunidade. Assim, o Estado chinês, através da sua embaixada em Portugal, é um activo promotor de uma tal iniciativa. Segundo o adido cultural da China em Lisboa, trata-se

de promover mais a cultura chinesa no exterior, porque depois do aumento importante do poderio económico o governo chinês está a dar cada vez mais importância à projecção da imagem do país no exterior. Então vem promovendo desde 2010 as celebrações do ano novo chinês (Adido cultural chinês, Lisboa).

De igual modo, a extensão entre a demografia da diversidade, campo social real das várias origens geográficas, e a semiótica da diversidade, proliferação de signos da diversidade, surge em materializações como o mercado de fusão do Martim Moniz, através do qual se associa a localização num bairro cuja presença de imigrantes é visível com a experiência da globalização localizada, 
através da possibilidade de experimentar várias gastronomias e sensibilidades culturais.

No caso do centro histórico de Lisboa, um território que se enquadra na estratégia da cultura como ativo, a interculturalidade tem vindo a tornar-se comercializável e a ser integrada nos fluxos globais de imagens na forma de uma "cena urbana" (NAVARRO et al., 2012), em que diversidade enquanto vantagem é estruturante na construção do bairro cultural.

A persistência dessa centralidade lisboeta culturalmente diversa tem vindo a ser activamente aproveitada para o marketing do lugar, de tal forma que a imagem de uma Lisboa cosmopolita tem sido inúmeras vezes formada metonimicamente como prolongamento desse eixo socioespacial.

A Lisboa das "muitas e variadas gentes" é captada pelo viver social da sua zona urbana mais diversa e transformada em poder imagético no marketing da cidade. Por exemplo, das três microcentralidades aventadas pela proposta de valor da Associação de Turismo de Lisboa (ATL), uma delas é o centro histórico (compreendendo Alfama/Castelo/Mouraria), e na identificação de estratégias de mercado surge a referência a "uma capital cosmopolita e tolerante marcada pela descoberta de novos mundos e original pela sua hospitalidade e multiculturalidade" (ATL, 2011, p. 18). Acrescente-se que uma das propostas que contudo não chegou a ter seguimento - era a criação na Praça do Comércio (agora relativa à zona da Baixa-Chiado) de "Transformação da praça [do Comércio] num espaço multicultural".

Todavia, o que esse enfoque mostra é a saliência do local no que concerne às estratégias autárquicas de formulação de identidades dos bairros e das suas articulações com a circulação imagética transnacionais, nomeadamente branding urbano e marketing turístico. O que isto significa é a incorporação plena das expressões culturalmente diversas nas políticas actuais de crescimento económico urbano. Como tínhamos visto para Buenos Aires, a intensificação da produção simbólica da diversidade, através de feiras, exposições, e todo o lado artístico-performativo, insere-se directamente em estratégias que visam articular espaços e mercado. Neste sentido, longe de ser um template de desenvolvimento europeu sob os auspícios de uma determinada política intercultural para as cidades europeias (iniciado através do Intercultural Cities, de 2008), como querem Abdou e Geddes (2017), ele surge claramente como resultado da circulação de um template para a competitividade urbana global.

No entanto, quer isto dizer que os imigrantes são vítimas passivas de tais processos? Como no caso de Buenos Aires, os imigrantes têm integrado e 
promovido tais dinâmicas, o que significa que a versão segundo a qual as celebrações, ou expressões culturais imigrantes, seriam ou contra-hegemónicas opondo-se a processos de regeneração ou subsistências tradicionais que resistiam às pressões assimilacionistas por parte da sociedade de acolhimento, não colhem mais no panorama actual.

O testemunho de uma bangladeshiana especializada em design de roupa ilustra essa imbricação. Segundo ela, sempre que há um desfile associado a uma das iniciativas interculturais promovidas pela Junta de Freguesia de Arroios, contactam-na para que desenhe os trajes tradicionais do Bangladesh e prepare as coreografias afetas. Foi o que se passou durante a "Volta ao Mundo em Arroios", iniciativa que compreende 11 semanas culturais (segundo dados de 2015) com espetáculos na Praça do Intendente (junto da Almirante Reis), cujos protagonistas são grupos imigrantes com as suas "performances" culturais. Por essa ocasião desfilaram crianças envergando os modelos criados por Yasmin (nome fictício) que se afirma como "representando as nossas roupas, os nossos tecidos e o meu design".

Sendo certo que não afirmamos que este seja o modo de inserção de todos os imigrantes, são caminhos possíveis proporcionados pelas dinâmicas políticas locais, pela relação entre a reestruturação contínua da cidade no âmbito de redes de poder e as dinâmicas espaciais da globalização.

Isso mesmo é refletido pela prática dos órgãos autárquicos de Arroios ao pretenderem reinventar a identidade do bairro enquanto intercultural (OLIVEIRA, 2019). Dentro dessa orientação cabe construir uma visão baseada nos valores da nova identidade de Arroios. Ou seja, um branding através do qual Arroios se torne uma entidade imediatamente apreensível. Nessa "visão" a diversidade cultural, cosmopolita, assumiu um papel central.

O facto de nós sermos, digamos, a zona da cidade, a Junta de Freguesia, com mais nacionalidades presentes, aqui, a viver, faz de nós, de facto, um lugar de inclusão, não é? (...) - agora falando mais do ponto de vista do marketing - é esse o nosso posicionamento diferenciador, relativamente à Estrela ou relativamente a Alvalade ou relativamente a Santo António [outros bairros lisboetas]. (...) Depois traduz-se, também, é um lugar, dentro da cosmopolita Lisboa, Arroios é o lugar mais cosmopolita. (Colaborador da Junta de Freguesia de Arroios).

A nova perceção alicerça-se, por conseguinte, na singularização de Arroios. A outrora imagem estigmatizada da zona foi gradualmente sendo reinventada pela forma como se combinam tradição histórica e as "paisagens globalizadas" 
trazidas pelos fluxos migratórios que não se esgotam apenas na imigração laboral, mas abarcam fluxos de mobilidade tão diversos quanto estudantes internacionais ou gentrificadores transnacionais. Se a tradição se mantém como atributo de tipicidade do local, ela tem, no entanto, dado lugar à simbiose entre turistificação e diversificação cultural.

\section{Conclusão}

Em termos muito sumários, podemos observar os dois cenários aqui abordados como paisagens de consumo (do original landscapes of consumption (RITZER, 2005)). Com efeito, a combinação entre as iniciativas de visibilização da diversidade e os espaços em que estas ocorrem sugere a mimetização de modelos dentro de uma economia globalizada em que os princípios e as estratégias se assemelham, porque possuem os mesmos objectivos de gerar ganhos económicos e simbólicos. Encontramos assim a incorporação das expressões da diversidade cultural em agendas desenvolvimentistas cujo perfil segue, em geral, linhas idênticas de orientação e suas premissas.

A saber, a diversidade cultural entra nos mecanismos de turistificação, marketização e embelezamento dos centros urbanos como activo cujo potencial é explorável em qualquer uma dessas dimensões. O que elas têm em comum é fazerem parte de uma ideia global de empreendedorismo urbano. E esta passa tanto pelos agentes promotores do desenvolvimento urbano como pelos actores da imigração e diversidade cultural. Essa comercialização da diversidade prima pela retórica da excepcionalidade, tanto em nível local como nacional, apelando, contudo, sempre às mesmas formas práticas.

A cidade pós-colonial que carregava o lastro do império de antanho dá gradualmente lugar à imagem da cidade cosmopolita aberta ao mundo. Essa é uma nova "estrutura de pensamento sobre a cidade" (BIANCHINI, 2006), que é reinvestida pelas práticas e percepções dos seus novos moradores e agentes. O reaproveitamento estratégico da diversidade demográfica presente no território lisboeta, quer seja pelas visitas guiadas promovidas por organizações do terceiro sector quer pela paleta multicultural das iniciativas culturais, fixa a imagem de uma cidade de mistura onde todas as tendências confluem. Do mesmo modo, a translação da diversidade imigrante das periferias para o centro de Buenos Aires, em formatos festivos e folclóricos, imprime à cidade uma sedução cosmopolita cujo objectivo é fascinar turistas e transeuntes, aproveitando simultaneamente para reproduzir mercados de cunho étnico. A diversidade cosmopolita é integrável nesses mesmos processos situados, mas 
de maneira formatada segundo o uso da cultura como parte da regeneração urbana. Um tal uso expande as expressões culturais através da sua visibilização controlada, ou seja, as formas que estas tomam são imediatamente ajustáveis ao "cosmopolitismo estético" (URRY, 2003) e acomodadas ao mercado. A espectacularização não é forçosamente um objecto de crítica.

Como assinalado por Raco, as estratégias em voga para cosmopolitizar a cidade associam-se estreitamente a um certo pragmatismo economicista de pendor neoliberal. Sendo a cultura em abstracto equacionada no planeamento estratégico urbano "como um recurso, uma oportunidade e uma estratégia de inclusão social" 17, a diversidade cultural decorrente de diferenças etnicizadas é incorporada neste novo regime de diversidade (RACO, 2017) através de modalidades criativas e artísticas. Aqui devemos ter em atenção uma distinção fundamental. Entre diversidade enquanto fenómeno empírico e semiótica da diversidade, ou seja, uma diversidade apenas composta pelos sinais de uma diversidade genérica. Uma hipótese mais crítica perspectiva a exploração da "diversidade cultural" como ersatz para "a fealdade moral da pobreza" servindo-se do apelo estético dessa mesma diversidade (BAUMAN, 2011, p. 46). Porém, de um ângulo diferente, a articulação entre estetização e experiência cultural torna-se a única possível na actual configuração de governança e poder. E esta encontra-se estreitamente associada às profundas modificações estruturais impressas pelas políticas de regeneração dos centros urbanos.

\section{Referências}

ABDOU, Leila Hadj; GEDDES, Andrew.

(2017 october). Managing superdiversity? Examining the intercultural policy turn in Europe. Policy \& Politics, vol. 45, n. 4, p. 493510(18) https://doi.org/10.1332/030557317X150166 76607077.

AHMED, Sara; SWAN, Elaine. (2006). Doing Diversity. Policy Futures in Education. vol. 4, n. 2, p. 96-100.
ALBERTO, P. N.; ELENA, Eduardo.

(2016). Introduction: The shades of the nation", in Paulina N. Alberto and Eduardo Elena (eds) Rethinking race in Modern Argentina, Cambridge: CUP, p. 1-24a .

CAPONIO, Tiziana; RICUCCI, Roberta.

(2015). Interculturalism: a policy instrument supporting social inclusion? In Interculturalism in Cities Ricard Zapata-Barrero (ed.). Cheltenham: Edward Elgar. p.20-34.

\footnotetext{
${ }^{17}$ cit in Hacia el Plan Estratégico de la ciudad de Buenos Aires 2030. Estrategias para avanzar en la planificación participativa.
} 
Di VIRGILLIO, María; MARCOS, Mariana; MERA, Gabriela.

(2015). "Las ciudades dentro de la ciudad: características sociodemográficas y habitacionales de la Ciudad de Buenos Aires según sus tipos de hábitat". In Población de Buenos Aires 12 (22), p. 33-57

FELDMAN-BIANC0, Bela.

(2009). Reinventando a localidade: globalização heterogênea, escala da cidade e a incorporação desigual de migrantes transnacionais. Horiz. Antropol. vol.15, n.31, p. 19-50.

FINCHER, Ruth; IVESON, Kurt; LEITNER, Helga; PRESTON, Valerie.

(2014). Planning in the multicultural city: Celebrating diversity or reinforcing difference? Progress in Planning. 92, p. 1-55.

FLORIDA, Richard.

(2002). The Rise of the Creative Class: And How it is Transforming Work, Leisure, Community and Everyday Life. Basic Books: New York.

FRANTZ, Monica de.

(2018). Tourism marketing and urban politics: cultural planning in a European capital. Tourism geographies, vol. 20, n. 3, p. 481-503.

HARVEY, David.

(1989). "From managerialism to entrepreneurialism: the transformation in urban governance in late capitalismo". Geografiska Annaler B. vol. 71, p. 3- 17

(2001). The art of rent. Globalization and commodification of culture". In Spaces of capital - Towards a critical geography, Nova Iorque: Routledge, p. 394-411.

JUDD, Denis R.

(2003) .Visitors and Special Ecology of the City" in Lilly M. Hofman, Susan Fanstein e Denis R. Judd (eds) Cities and Visitors. Regulating people, markets and city space. Malden: Blackwell Publishing.

LIBERMAN, A. M.

(2016). “El Primer Plan Estratégico de Cultura de la Ciudad Autónoma de Buenos Aires. Ejes cruciales en materia de transformación de las políticas públicas para la adolescencia y juventud 2030". Comunicación presentada al VII Congreso Internacional en Gobierno, Administración y Politicas Públicas, Buenos Aires, Octobre.

KALTMEYER, Olaf (ed.).

(2011). Selling EthniCity. Urban Cultural Politics in the Americas, London: Ashgate.

NAVARRO, Clemente L.; CLARK, Terry N., SILVER, Daniel.

(2012). Las dimensiones e el carácter cultural de la ciudad", in Las dimensiones culturales de la ciudad, Clemente J. Navarro (coord.) Madrid: Catarata, p. 13-45.

\section{OLIVEIRA, Nuno.}

(2013). Lisboa redescobre-se. a governança da diversidade cultural na cidade pós-colonial", in Cidades e Império. Dinâmicas coloniais e reconfigurações pós-coloniais, Elsa Peralta e Nuno Domingos (orgs). Lisboa: Edições 70, p. 558-602.

(2015). Identificações Coletivas e Gestão da Diversidade Étnico-Cultural: Dinâmicas Sociais Contrastantes entre Portugal e o Brasil, in Dados - Revista de Ciências Sociais, vol. 58, n.4, p. 1099-1130. http://dx.doi.org/10.1590/00115258201567.

(2019 december). Cosmopolitan Lisbon and the allure of diversity. Cidades, Comunidades $e$ Territórios, 39, p. 115-128.

OLIVEIRA, Nuno; PADILLA, Beatriz.

(2017 october). Integrating superdiversity in local governance. The case of Lisbon's innercity. Policy and Politics, vol. 45, n. 4, p. 605622(18), doi: https://doi.org/10.1332/030557317X14 835601760639.

RACO, Mike.

(2018). Critical urban cosmopolitanism and the governance of urban diversity in European Cities", European Urban and Regional Studies, vol. 25, n. 1. pp. 8-23.

RITZER, George.

(2005). Enchanting a disenchanted world. Revolutionizing the means of consumption. California: Pine Forge Press. 
SEGAT0, Rita

(2007). La Nación y sus Otros. Raza, etnicidad y diversidad religiosa en tiempos de políticas de la identidad. Buenos Aires: Prometeo Libros.

SYRETT, S.; SEPULVEDA, Leandro.

(2011). Realising the diversity dividend: population diversity and urban economic development", Environment and Planning, vol. 43, p. 487-504.

WESSENDORF, $\mathrm{S}$.

(2013). Commonplace diversity and the 'ethos of mixing': perceptions of difference in a London neighborhood". Identities, vol. 20, n. 4 , p. 407-422.

WISE, A.; VELAYUTHAM, S.

(2014). Conviviality in everyday multiculturalism: Some brief comparisons between Singapore and Sydney". European Journal of Cultural Studies, August. vol. 17, 4, p. 406-430.

W00D, Phil.

(2012). Challenges of Governance in Multi-Ethnic Cities", in Helmut K. Anheier e Yudhisthir Raj Isar (eds). Cultures and Globalization: Cities, Cultural Policy and Governance, p. 44- 60.
WOOD, P.; LANDRY, C.

(2008) The Intercultural City: Planning for Diversity Advantage. London: Earthscan.

VICKERY, Roy; VICKERY, Monica. (1974)

(1974). Chinese New Year Celebrations in London 1971-1973. Floklore, vol. 85, 1, p. 42-45.

VERTOVEC, Steven.

(2007). Super-diversity and its implications. Ethnic and Racial Studies 30, p. 1024-1054.

(2012). Diversity and the Social Imaginary. European Journal of Sociology, n.53, p. 287-312. doi:10.1017/S000397561200015X.

ZUKIN, Sharon.

(1988). Loft living: Culture and Capital in Urban Change, Londres, Radius/Hutchinson.

(1991). Landscapes of power. Berkeley and L.A.: UCP.

(1995) The cultures of cities. Malden: Blackwell.

\section{Recebido em}

março de 2020

Aprovado em

novembro de 2020 